\title{
Assemblages of terrestrial isopods (Isopoda, Oniscidea) in a fragmented forest landscape in Central Europe
}

\author{
Karel Tajovský', Jan Hošek², Jeňýk Hofmeister², Jolanta Wytwer ${ }^{3}$ \\ I Institute of Soil Biology, Biology Centre of the Academy of Sciences of the Czech Republic, Na Sádkách 7, 370 \\ 05 České Budějovice, Czech Republic 2 Ecological Services Ltd., Areál ČOV, 26801 Hoŕovice, Czech Republic \\ 3 Museum and Institute of Zoology, Polish Academy of Sciences, Wilcza 64, 00-679 Warszawa, Poland \\ Corresponding author: Karel Tajovský (tajov@upb.cas.cz) \\ Academic editor: S. Taiti | Received 29 November 2011 | Accepted 26 January 2012 | Published 20 March 2012 \\ Citation: Tajovský K, Hošek J, Hofmeister J, Wytwer J (2012) Assemblages of terrestrial isopods (Isopoda, Oniscidea) in \\ a fragmented forest landscape in Central Europe. In: Štrus J, Taiti S, Sfenthourakis S (Eds) Advances in Terrestrial Isopod \\ Biology. ZooKeys 176: 189-198. doi: 10.3897/zookeys.176.2296
}

\begin{abstract}
Terrestrial isopods were collected in 13 forest fragments differing in area (within the range of 0.1 and 254.5 ha), shape and composition of forest vegetation (thermophilous oak, mesophilous oak-hornbeam, thermophilous oak-hornbeam, acidophilous oak, basiphilous oak, beech oak-hornbeam, moist mixed deciduous forest, plantations of deciduous and coniferous trees), all situated in the Český kras Protected Landscape Area, Czech Republic, Central Europe. Number of sites sampled in each fragment of forest depended on its size and ranged from 1 to 7 . Altogether 30 sites were sampled. Soil samples ( 5 per site collected twice a year) and pitfall trapping ( 5 traps per site in continuous operation throughout a year) during 2008-2009 yielded a total of 14 species of terrestrial isopods. The highest densities and highest epigeic activities of terrestrial isopods were recorded in the smallest fragments of woodland. Although a wider range of habitats were sampled in the larger fragments of woodland there was not a greater diversity of species there and the population densities and epigeic activities recorded there were lower. Porcellium collicola was most abundant in small fragments of woodland regardless the vegetation there. Armadillidium vulgare and Protracheoniscus politus were statistically more abundant in the larger fragments of woodland. The results indicate that forest fragmentation does not necessarily result in a decrease in the species richness of the isopod assemblages in such habitats.
\end{abstract}

\section{Keywords}

Woodlice, densities, epigeic activity, pitfall trapping, Armadillidium vulgare, Porcellium collicola

Copyright Karel Tajovský et al. This is an open access article distributed under the terms of the Creative Commons Attribution License 3.0 (CC-BY), which permits unrestricted use, distribution, and reproduction in any medium, provided the original author and source are credited. 


\section{Introduction}

Fragmentation is a natural feature of most landscapes (Tews et al. 2004). In addition to the possible decrease in biodiversity due to loss of habitats and extinction of sensitive species (Henle et al. 2004), habitat fragmentation has weaker positive than negative effects on biodiversity (Fahrig 2003). Invertebrates may react to habitat fragmentation differently (Ewers and Didham 2006) as it can positively influence the development and diversification of habitats and more-specialized species may be more susceptible to these processes than generalists (Didham et al. 1996).

The Central European landscape has been influenced by human activities for millennia. It is characterised by intensive land-use and a continuing trend of habitat destruction. Originally the landscape in the temperate zone was covered with woodland. Present forest system consists of patches differing in shape, size and vegetation in which there is often a higher biodiversity than in the majority of open and usually agriculturally exploited areas. Fragmentation of remaining areas of natural, semi-natural and other well-preserved patches of forest represents a major threat to biodiversity (Tscharntke et al. 2002). However, it is unknown whether such processes also influence the diversity of soil invertebrates (Didham et al. 1996). Although some studies suggest that soil organisms, in general, are not sensitive to habitat fragmentation, even at a small scale (Rantalainen et al. 2008, David and Handa 2010), this is not the case for rare, more specialised species or those with a poor dispersal ability (Tscharntke et al. 2002).

In the assessment of the effect of forest fragmentation on vegetation and different groups of aboveground and soil invertebrates, terrestrial isopods are used as a model group of soil saprophagous macro-invertebrates. Terrestrial isopods are also potential bio-indicators of environmental quality in natural as well as disturbed and polluted habitats (Dallinger et al. 1992, Paoletti and Hassall 1999). Presented in this paper is a comparison of the assemblages of terrestrial isopods in forest fragments differing in area and other structural parameters. The aim of the paper is to assess how the above (epigeic activity) and belowground (soil) parts of assemblages of terrestrial isopods react to forest fragmentation.

\section{Materials and methods}

This research was undertaken in the fragmented landscape of the Český kras Protected Landscape Area, Central Bohemia, Czech Republic. In this area the bedrock is predominantly limestone and there are numerous fragments of formerly more integrated woodlands. There is little diversity in the structure of the vegetation in the smaller fragments, which contrasts with the mosaic character and higher spectrum of plant associations with a long history of diverse management and development in the larger forest units. During the period 2008-2009 soil sampling and pitfall trapping were used to determine the assemblages of terrestrial isopods in 13 fragments of forest that ranged in area between 0.1 and $254 \mathrm{ha}$. A total of 30 sites were sampled (Table 1). The 


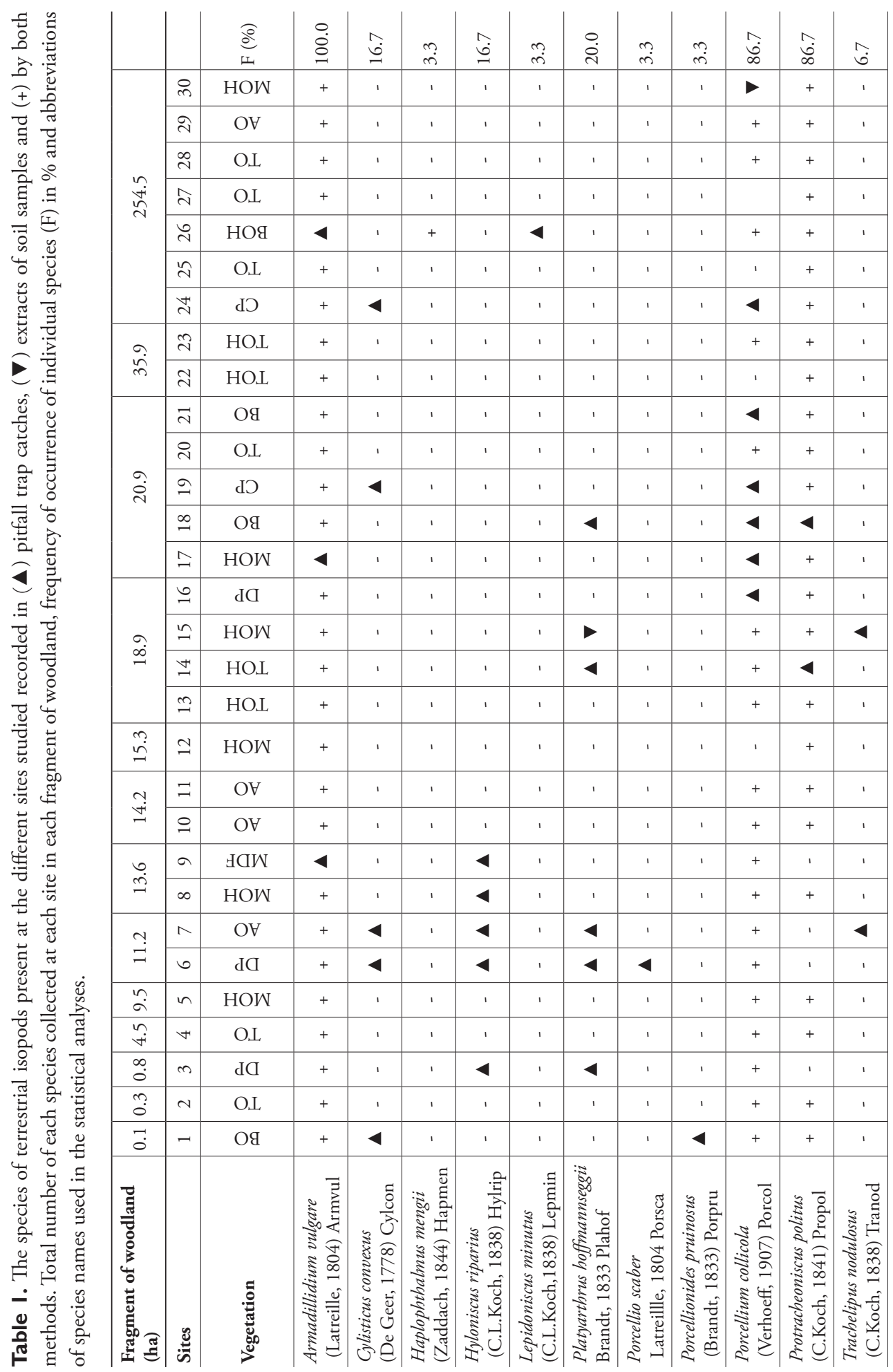




\begin{tabular}{|c|c|c|c|c|c|c|c|}
\hline & & $\frac{\widehat{\varrho}}{4}$ & $\hat{\sigma}$ & $\stackrel{0}{\circ}$ & $\widehat{\widehat{\sigma}}$ & & \\
\hline \multirow{7}{*}{$\stackrel{+}{\stackrel{\sim}{*}}$} & $\stackrel{n}{n}$ & HOW & 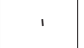 & 4 & ' & 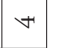 & \\
\hline & iे & $\mathrm{OH}$ & ' & 4 & ' & 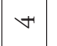 & \\
\hline & $\stackrel{\infty}{\sim}$ & $\mathrm{OL}$ & ' & 4 & ' & + & \\
\hline & $\hat{\imath}$ & $\mathrm{OL}$ & ' & 4 & 4 & $\psi$ & $\infty$ \\
\hline & i & HOg & ' & 4 & 4 & 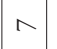 & \\
\hline & $\approx$ & OL & ' & 4 & I & $m$ & \\
\hline & $\stackrel{せ}{\sim}$ & dつ & ' & 4 & ' & $n$ & \\
\hline \multirow{2}{*}{$\dot{n}$} & $\ddot{\sim}$ & HOL & ' & 4 & ' & $*$ & \\
\hline & ส & HOL & ' & 4 & ' & $n$ & \\
\hline \multirow{5}{*}{ ڤे } & $\vec{N}$ & Oq & ' & 4 & ' & 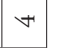 & \\
\hline & ㄱ. & $\mathrm{OL}$ & ' & + & ' & $*$ & \\
\hline & $\approx$ & dつ & ' & + & ' & $n$ & $r$ \\
\hline & $\stackrel{\infty}{\sim}$ & Oq & , & ' & $\checkmark$ & $n$ & \\
\hline & $\approx$ & HOW & ' & 4 & ' & 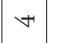 & \\
\hline \multirow{4}{*}{$\stackrel{\infty}{\infty}$} & 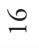 & dC & ' & 4 & ' & 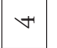 & \\
\hline & $\cong$ & HOW & ' & 4 & ' & 0 & \\
\hline & \pm & HOL & ' & ' & ' & $W$ & , \\
\hline & 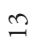 & HOL & , & 4 & ' & 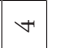 & \\
\hline$\stackrel{n}{n}$ & $\simeq$ & HOW & ' & 4 & , & $n$ & $m$ \\
\hline \multirow{2}{*}{$\stackrel{\sim}{\underset{H}{*}}$} & $=$ & OH & ' & 4 & ' & W & \\
\hline & 으 & $\mathrm{OH}$ & ' & 4 & ' & $*$ & \\
\hline \multirow{2}{*}{$\stackrel{\circ}{\stackrel{\longrightarrow}{\rightarrow}}$} & $a$ & HबW & ' & 4 & + & in & $1 \infty$ \\
\hline & $\infty$ & HOW & ' & ' & $>$ & $n$ & \\
\hline \multirow{2}{*}{$\stackrel{\sim}{=}$} & $\wedge$ & $\mathrm{OH}$ & ' & ' & ' & 6 & - \\
\hline & 6 & dC & 4 & 4 & ' & $\infty$ & 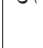 \\
\hline$\tilde{\sigma}$ & in & HOW & ' & + & ' & 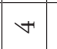 & $\psi$ \\
\hline$\stackrel{n}{\forall}$ & $\checkmark$ & $\mathrm{OL}$ & ' & + & ' & 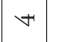 & $\checkmark$ \\
\hline$\stackrel{\infty}{\circ}$ & $n$ & dC & ' & 4 & ' & $n$ & in \\
\hline ? & N & $\mathrm{OL}$ & 4 & ' & ' & $W$ & $\psi$ \\
\hline $\overrightarrow{0}$ & - & oq & ' & ' & ' & $n$ & in \\
\hline 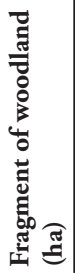 & 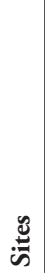 & 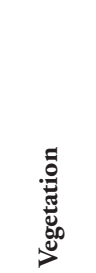 & 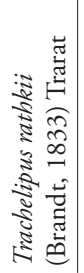 & 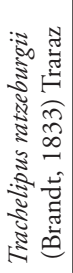 & 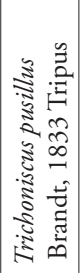 & 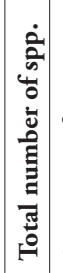 & 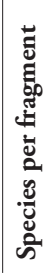 \\
\hline
\end{tabular}


sites sampled were representative of the seven forest plant associations characteristic of the area: thermophilous oak (TO), mesophilous oak-hornbeam $(\mathrm{MOH})$, thermophilous oak-hornbeam (TOH), acidophilous oak (AO), basiphilous oak (BO), beech oakhornbeam $(\mathrm{BOH})$, moist mixed deciduous forest $(\mathrm{MDF})$ and plantations of deciduous (DP) and coniferous (CP) trees. At each site, five soil samples (area of each $625 \mathrm{~cm}^{2}$, depth ca $10 \mathrm{~cm}$ ) were collected in spring and autumn and isopods were heat extracted using a modified Kempson apparatus (Kempson et al. 1963). In addition, five pitfall traps (each with a diameter of $9 \mathrm{~cm}$ and containing a solution of formaldehyde) were used to catch isopods, which were collected from the traps once a month for a period of year at each study site. Additional soil samples were collected at each site and used to determine the chemical characteristics of the uppermost soil layers (soil $\mathrm{pH}, \mathrm{C}: \mathrm{N}$ ratio and $\mathrm{Ca}^{2+}$ content).

The data on the isopod assemblages were evaluated with respect to the parameters of the sites and fragments. Multivariate analyses: DCA and RDA were used to consider gradient data length and importance of factors shaping the terrestrial isopod assemblages (13 variables). Methods of material collection (pitfall traps and soil samples) were treated as covariables in block analysis. The importance of the explanatory variables considered was examined during forward selection procedure in RDA. The analyses were done using the software for canonical community ordination - Canoco 4.5/CanoDraw 4.14 (ter Braak, Šmilauer 2002).

\section{Results}

During the course of the two years of this study we collected 28 thousand isopods (1,839 were extracted from soil samples and 26,398 were caught in the pitfall traps) belonging to 14 species (Table 1). The most abundant of which were Armadillidium vulgare, Porcellium collicola and Protracheoniscus politus. The first species was recorded at all the sites and the frequency of occurrence of the other two species was $86.7 \%$. High frequency of occurrence $(80.0 \%$ ) was recorded also for Trachelipus ratzeburgii. Whereas the first three species were generally predominant in both the pitfall trap catches and soil extracts Trachelipus ratzeburgii mainly inhabits aboveground microhabitats and is frequently found under the bark of decaying wood. Thus, it was repeatedly caught in pitfall traps, but often absent in extracts of soil samples.

Individual sites were frequently inhabited by only four or five species. The highest number of species was found in both small and large fragments ( 9 and 8 species in fragments of 11.2 and 254.5 ha, respectively).

Even the smallest fragments, which varied little in the structure of their vegetation, harboured high population densities of a high number of species. Both, the highest population density (549 individuals per $\mathrm{m}^{2}$ ) and epigeic activity (4,206 individuals per 5 traps per year) were recorded in the smallest fragments (Figure 1 and 2). In spite of sampling a greater number of sites in the medium-sized and large fragments of forest the lowest population densities and epigeic activities were recorded there. 

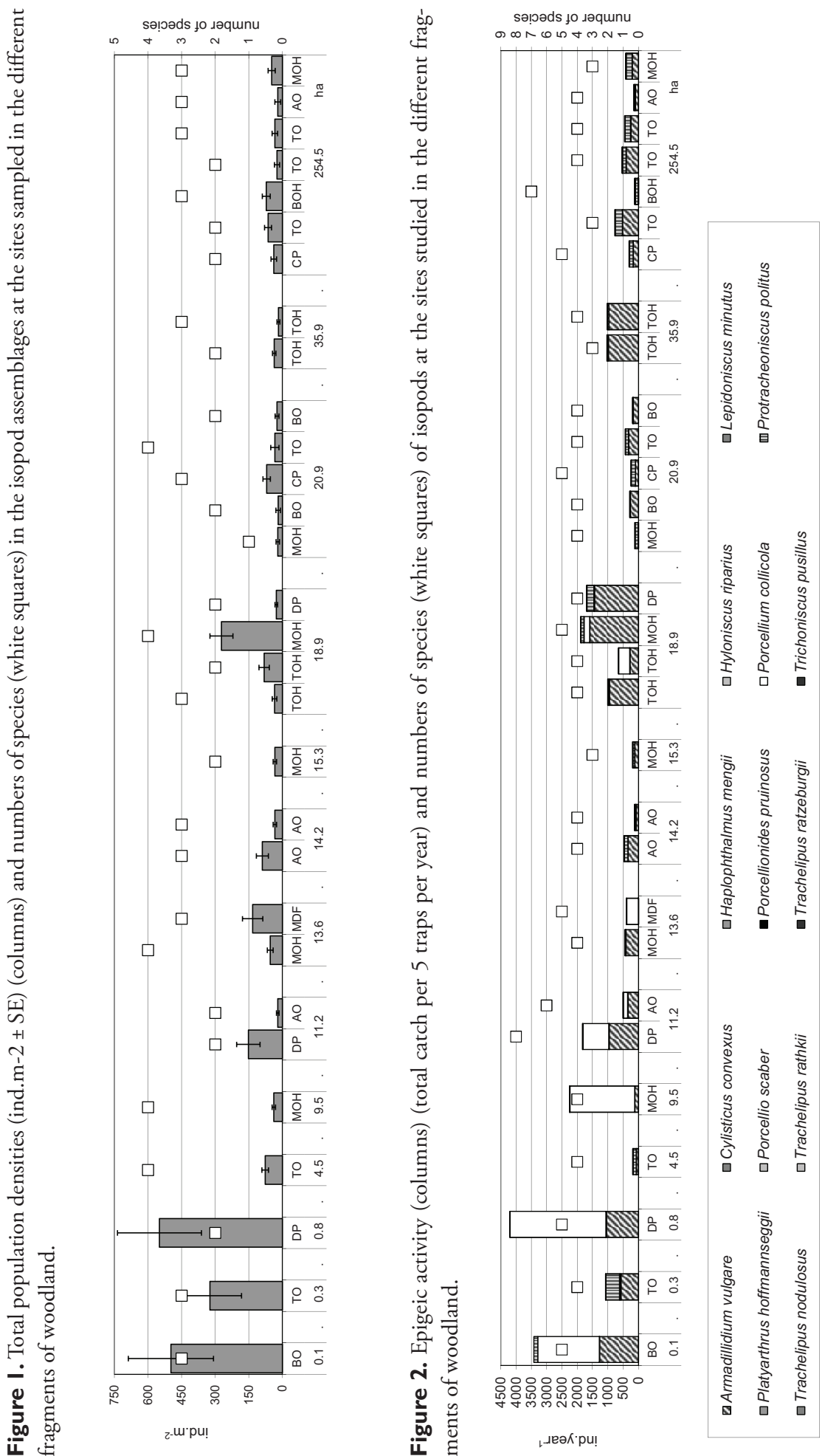
Since the weighted-average Detrended Correspondence Analysis (DCA) indicates that isopods have a rather low beta-diversity, i.e. a 'short gradient' $(=2.265)$, where most species show a linear response to the explanatory variables considered (Leps and Smilauer 2003), a triplot of the Redundancy Analysis (RDA) is presented (Figure 3). This indicates
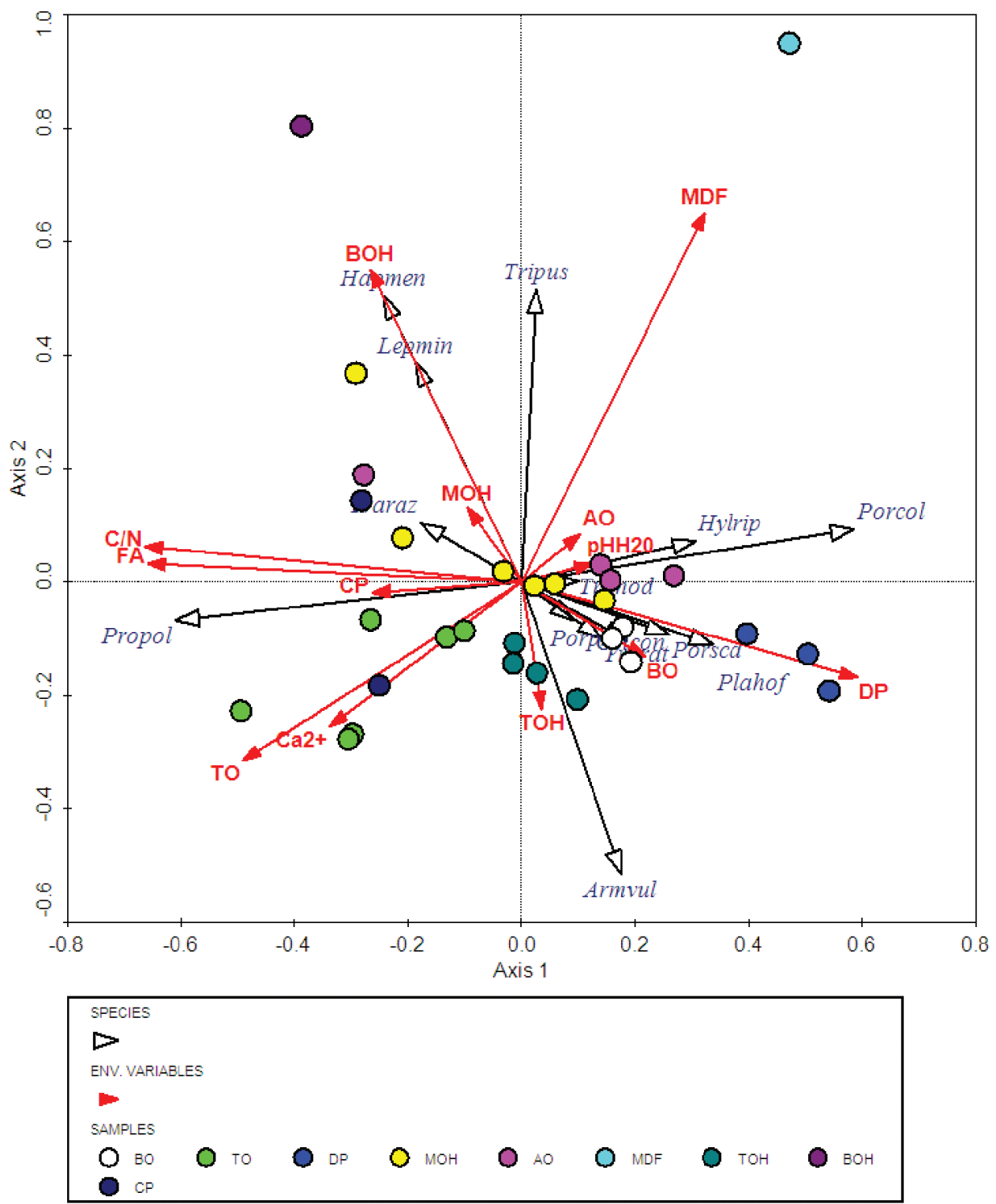

Figure 3. A triplot of the RDA block analyses of terrestrial isopod assemblages at the sites studied. For the abbreviations of the species see Table $1, \mathrm{FA}$ - fragment area, $\mathrm{C} / \mathrm{N}$ - carbon-nitrogen ratio, Ca2+calcium content of the soil, $\mathrm{pHH} 2 \mathrm{O}$ - soil acidity. TO, $\mathrm{MOH}, \mathrm{TOH}, \mathrm{AO}, \mathrm{BO}, \mathrm{BOH}, \mathrm{MDF}, \mathrm{DP}$ and $\mathrm{CP}$ - vegetation at the different sites, see text. 
that the $1^{\text {st }}$ canonical axis is correlated negatively mainly with the area of the fragments (FA) and C:N ratio (Figure 3). Most species are significantly positively correlated with the $1^{\text {st }}$ axis. Protracheoniscus politus is correlated positively with size of a fragment and the C:N ratio whereas the second most abundant species, Porcellium collicola, is negatively correlated with these variables. The abundance of Armadillidium vulgare, which was abundant at most sites, was not associated with either FA or the C:N ratio. The two relatively rare species Haplophthalmus mengii and Lepidoniscus minutus were mainly associated with beech oak-hornbeam sites $(\mathrm{BOH})$ and low population densities of the hygrophilous Trichoniscus pusillus and Hyloniscus riparius partly with moist deciduous forest.

The forward selection procedure revealed that the area of a fragment was the most important significant variable (marginal effect: $\lambda 1=0.1$ ) determining the assemblage of terrestrial isopods (Table 2). The $\mathrm{C}: \mathrm{N}$ ratio was highly correlated with FA and also may influence the variability in terrestrial isopod assemblages (marginal effect: $\lambda 1=$ 0.1 ), however this association is not statistically significant.

Table 2. The results of the verification of the explanatory variables using the Monte Carlo permutation test (499 permutations under reduced model) in the forward selection procedure of RDA (CANOCO 4.5); significant variables are in bold.

\begin{tabular}{|c|c|c|c|c|c|c|c|}
\hline \multicolumn{3}{|c|}{ Marginal Effects } & \multicolumn{5}{|c|}{ Conditional Effects } \\
\hline Variable & Var.N & Lambda1 & Variable & Var.N & LambdaA & $\mathrm{P}$ & $\mathrm{F}$ \\
\hline FA & 4 & 0.10 & FA & 4 & 0.10 & 0.002 & 8.51 \\
\hline C:N & 3 & 0.10 & MDF & 10 & 0.06 & 0.002 & 4.94 \\
\hline DP & 7 & 0.08 & DP & 7 & 0.05 & 0.008 & 5.53 \\
\hline TO & 6 & 0.07 & BOH & 13 & 0.04 & 0.020 & 3.60 \\
\hline MDF & 10 & 0.06 & TO & 6 & 0.02 & 0.076 & 2.45 \\
\hline BOH & 13 & 0.05 & $\mathrm{MOH}$ & 8 & 0.01 & 0.264 & 1.22 \\
\hline $\mathrm{Ca} 2+$ & 2 & 0.03 & $\mathrm{CP}$ & 12 & 0.02 & 0.192 & 1.48 \\
\hline $\mathrm{CP}$ & 12 & 0.02 & $\mathrm{TOH}$ & 11 & 0 & 0.440 & 0.83 \\
\hline $\mathrm{BO}$ & 5 & 0.02 & $\mathrm{C} / \mathrm{N}$ & 3 & 0.01 & 0.398 & 1.00 \\
\hline $\mathrm{TOH}$ & 11 & 0.01 & $\mathrm{BO}$ & 5 & 0.02 & 0.144 & 1.82 \\
\hline $\mathrm{MOH}$ & 8 & 0.01 & $\mathrm{Ca} 2+$ & 2 & 0.02 & 0.158 & 1.65 \\
\hline $\mathrm{pHH}_{2} 0$ & 1 & 0.01 & $\mathrm{pHH}_{2} 0$ & 1 & 0 & 0.962 & 0.17 \\
\hline $\mathrm{AO}$ & 9 & 0 & & & & & \\
\hline
\end{tabular}

\section{Discussion}

The three predominant species are differently associated with the area (FA), C:N ratio, soil acidity $(\mathrm{pH})$ and $\mathrm{Ca} 2+$ content of the soil in the fragments of woodland studied. The isopods Armadillidium vulgare and Porcellium collicola were more abundant in small fragments of woodland. Nevertheless, Armadillidium vulgare was frequently recorded in the largest fragments. Protracheoniscus politus was most abundant in large fragments of woodland. The RDA also reveals a close association of Armadillidium vulgare and Porcellium collicola with fragments of woodland with base rich soils (high $\mathrm{pH}$ ), whereas for Protracheoniscus politus this association is less pronounced. Some spe- 
cies (e.g. Cylisticus convexus, Trachelipus ratzeburgii, Porcellio scaber, Trachelipus nodulosus and Trachelipus rathkii) may be more acid tolerant.

Although Armadillidium vulgare was abundant at most of the sites studied, both in small and large fragments of woodland (see Figure 2), Porcellium collicola was most abundant in the small fragments of woodland irrespective of the vegetation at these sites. The third most frequent species, Protracheoniscus politus, was most closely associated with large fragments of woodland. Its occurrence in some of the smaller fragments may be attributed to the historical fact that mainly due to man the forest in this area was fragmented into small separate wooded islands during the course of the past century.

The isopod communities in the larger fragments of forest, which have the greatest diversity of habitats, were the most homogeneous. Surrounding open grassland and forest-steppe calcareous biotopes, including diverse man-made habitats, did not enrich the diversity of isopods recorded in forest fragments as synanthropic species were always in the minority.

The abundance and composition of the species in isopod assemblages differed depending on the plant associations in the fragments of woodland sampled, but in vegetation types $\mathrm{TO}, \mathrm{TOH}$ and $\mathrm{AO}$ they were very similar.

Terrestrial isopods do not appear to be more sensitive to fragmentation than other saprophagous invertebrates, such as millipedes (David and Handa 2010). The fragmentation of shrubby habitats in urban areas does not reduce the epigeic activity of Armadillidium vulgare and Porcellio laevis (Bolger et al. 2000). Apparently the critical fragment size for these animals is very small or they are better at dispersing than generally thought (David and Handa 2010).

Our results indicate that forest fragmentation does not necessarily result in a decrease in the size of terrestrial isopod assemblages, but their dominance structure may be affected, which is in accordance with the results presented in the David and Handa's (2010) review. The determination of the sensitivity of different species to fragmentation is dependent on further analyses of the changes in the population parameters associated with other environmental characteristics that occur following fragmentation.

\section{Acknowledgements}

The research was funded by the Ministry of Environment, No. SP/2d3/139/07 and the AS CR, Research Plan No. AV0Z60660521. The authors thank anonymous reviewers for valuable suggestions and comments on the manuscript and Anthony F. G. Dixon, Norwich, UK, for critical revision of the text.

\section{References}

Bolger DT, Suarez AV, Crooks KR, Morrison SA, Case TJ (2000) Arthropods in urban habitat fragments in southern California: area, age, and edge effects. Ecological Applications 10: 1230-1248. doi: 10.1890/1051-0761(2000)010[1230:AIUHFI]2.0.CO;2 
Dallinger R, Berger B, Birkel S (1992) Terrestrial isopods: useful bioindicators of urban metal pollution. Oecologia 89: 32-41. doi: 10.1007/BF00319012

David JF, Handa IT (2010) The ecology of saprophagous macroarthropods (millipedes, woodlice) in the context of global change. Biological Reviews 85: 881-895.

Didham RK, Ghazoul J, Stork NE, Davis AJ (1996) Insects in fragmented forests: a functional approach. Tree 11: 255-260. doi: 10.1016/0169-5347(96)20047-3

Ewers RM, Didham RK (2006) Confounding factors in the detection of species responses to habitat fragmentation. Biological Reviews 81: 117-142. doi: 10.1017/S1464793105006949

Fahrig L (2003) Effects of habitat fragmentation on biodiversity. Annual Reviev of Ecology Evolution and Systematics 34: 487-515. doi: 10.1146/annurev.ecolsys.34.011802.132419

Henle K, Davies KF, Kleyer M, Margules C, Settele J (2004) Predictors of species sensitivity to fragmenttion. Biodiversity and Conservation 13: 207-215. doi: 10.1023/B:BIOC.00000 $04319.91643 .9 \mathrm{e}$

Kempson D, Lloyd M, Ghelardi R (1963) A new extractor for woodland litter. Pedobiologia 3: $1-21$.

Leps J, Smilauer P (2003) Multivariate analysis of ecological data using CANOCO. Cambridge University Press.

Paoletti MG, Hassall M (1999) Woodlice (Isopoda: Oniscidea): their potential for assessing sustainability and use as bioindicators. Agriculture, Ecosystems and Environment 74: 157165. doi: 10.1016/S0167-8809(99)00035-3

Rantalainen M-L, Haimi J, Fritze H, Pennanen T, Setälä H (2008) Soil decomposer community as a model system in studying the effects of habitat fragmentation and habitat corridors. Soil Biology and Biochemistry 40: 835-863. doi: 10.1016/j.soilbio.2007.11.008

ter Braak CJF, Šmilauer P (2002) CANOCO Reference manual and CanoDraw for Windows User's guide: Software for Canonical Community Ordination (version 4.5). - Mictocomputer Power (Ithaca, NY, USA): 500 pp.

Tews J, Brose U, Grimm V, Tielbörger K, Wichmann MC, Schwager M, Jeltsch F (2004) Animal species diversity driven by habitat heterogeneity/diversity: the importance of keystone structures. Journal of Biogeography 31: 79-92. doi: 10.1046/j.0305-0270.2003.00994.x

Tscharntke T, Stefan-Dewenter I, Kruess A, Thies C (2002) Characteristics of insect populations on habitat fragments: A mini review. Ecological Research 17: 229-239. doi: 10.1046/j.1440-1703.2002.00482.x 